\title{
Proposed Definitions of Typical Lesions in Hidradenitis Suppurativa
}

\author{
Mathilde Daxhelet ${ }^{\mathrm{a}}$ Mariano Suppa $^{\mathrm{a}}$ Jonathan White ${ }^{\mathrm{a}}$ Farida Benhadou $^{\mathrm{a}}$ \\ Linnea Rishøj Thorlacius $^{\mathrm{b}} \quad$ Gregor B.E. Jemec $^{\mathrm{b}} \quad$ Véronique del Marmol $^{\mathrm{a}}$ \\ Jean Revuz ${ }^{\mathrm{c}}$ \\ ${ }^{a}$ Department of Dermatology, Université Libre de Bruxelles, Erasme Hospital, Brussels, Belgium; ${ }^{b}$ Department of

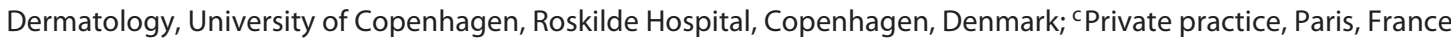

\section{Keywords}

Hidradenitis suppurativa · Acne inversa - Semiology ·

Definition · Description

\begin{abstract}
Background: Although not rare, hidradenitis suppurativa (HS) is often under-recognized by physicians. The diagnosis of HS is clinical via the recognition of lesions typical of the disease, but universally accepted definitions of these latter are currently lacking, which means that certain severity scores employed for HS classification/management are used differently by different physicians. Our aim was to develop a set of descriptive definitions and associated images of HS lesions, in order to enable doctors to better recognize and evaluate the disease. Methods: MEDLINE-available literature and dermatological textbooks on HS morphology were retrieved (January 1996 to February 2016). A preliminary set of definitions of HS typical lesions was created, including 10 terms. Each term was associated with a pathophysiological classification and an image. This preliminary set was shown during the 5th Conference of the European HS Foundation (EHSF). The physicians attending the event were invited to vote on each term and make comments via a voting sheet.
\end{abstract}

Results: A total of 81 physicians answered the questionnaire. Their agreement/disagreement rates and comments were used to obtain a revised set of definitions and images. Pathophysiological classifications were dropped. Conclusion: A user-friendly set of definitions/images of HS typical lesions was proposed and will need to be validated by further studies. This set could ultimately serve as a tool to better recognize, score, and assess treatment efficacy.

(c) 2020 S. Karger AG, Basel

\section{Introduction}

Hidradenitis suppurativa (HS) is a chronic skin disease characterized by painful, inflamed lesions located predominantly in the axillae, groins, and perineal/perianal areas. European studies estimate HS prevalence in various populations at $1-4 \%$ [1]. Despite this, HS frequently appears to be under-recognized by physicians, which is supported by the long delay in diagnosis [2]. Although the diagnosis of HS relies on clinical criteria only (i.e., the chronic-recurrent presence of HS typical lesions, distributed according to the typical topography of the disease) [3], agreement on definitions of HS typical lesions karger@karger.com

(C) 2020 S. Karger AG, Basel

Karger"
Mathilde Daxhelet

Department of Dermatology

Université Libre de Bruxelles, Erasme Hospital

Route de Lennik, 808, BE-1070 Brussels (Belgium)

daxheletmathilde@gmail.com 
Fig. 1. Flowchart of Materials and MethMEDLINE-available literature and dermatological textbooks on $\mathrm{HS}$ morphology were retrieved

(January 1996-February 2016)

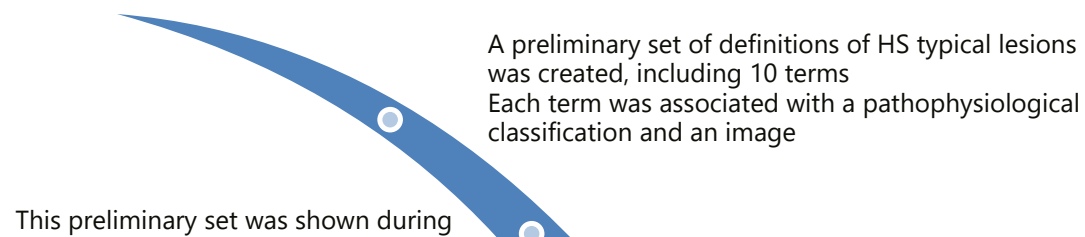
the 5th HS conference of the EHSF The physicians attending the event were invited to vote on each term and make comments via a voting sheet

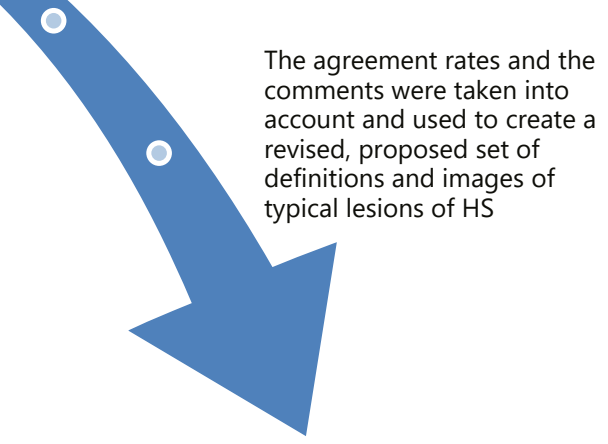

Proposed set of definitions of HS typical lesions ods.

appears to be low in daily practice. The number of publications concerning HS has constantly increased over the last 2 decades, but very few described what typical lesions of HS are. A list of lesions typical of the disease was provided by Jemec et al. [4] in 2006 accompanied by a partial description, but no complete definition. A list of lesions without accompanying definitions was also given by the modified Dessau definition [3]. Recently, Scheinfeld established an exhaustive atlas of images of typical lesions of HS, but with no definition [5].

Freysz et al. [6] made a systematic review of the terms used to describe HS in order to elaborate a glossary, but the terms abscess, scar, fistula, and comedo were excluded from it. Lipsker et al. [7] proposed new terms related to more severe cases of HS (such as multicord and multitun$n e l)$. van der Zee and Jemec [8] described 6 different types of clinical presentations of the disease, but the aim of their work was to focus more on pathophysiology than descriptive definitions.

The lack of accepted common definitions of HS typical lesions is likely to contribute to the problems experienced by patients such as the long delay in diagnosis, but it also explains why severity scores depending on lesion counts show great variation even among experts who commonly manage this disease [9]. Formal definitions of HS typical lesions may allow more precise and consistent scoring of the disease and, consequently, better treatment strategies, assessment of the treatment efficacy, and patients' follow-up.

The goal of this study was to develop a set of descriptive definitions and associated images of HS lesions, which may ultimately serve as a tool to help doctors to recognize and evaluate the disease better. To achieve this, we performed a survey of physicians attending the 5th Conference of the European HS Foundation (EHSF) [10].

\section{Materials and Methods}

For further details, see the online supplementary material (see www.karger.com/doi/10.1159/000507348for all online suppl. material) [3, 4, 6, 8, 10-17] (Fig. 1; Table 1a; suppl. Fig. 1).

\section{Results}

A total of 81 participants filled out the questionnaire. All of them were physicians. In detail, 61/81 (75.3\%) were dermatologists and 20/81 (24.7\%) were specialists in other fields. The median age of participants was 38 years (range 26-64 years). 
Table 1. Preliminary and proposed set of definitions and images of HS typical lesions

\begin{tabular}{l}
\hline a Preliminary set of definitions \\
\hline Definition \\
\hline NODULE \\
Palpable lesion, with a solid \\
content, round, and diameter \\
$>10 \mathrm{~mm}$
\end{tabular}

b Proposed set of definitions

Definition Image

NODULE

Palpable lesion, with a solid content, round rather than pointed, diameter $>10 \mathrm{~mm}$; usually deep seated, not raised; painful (spontaneously or on palpation) or not; inflammatory or not

\section{ABSCESS}

Palpable lesion, with a liquid content (pus) - and diameter $>10 \mathrm{~mm}$

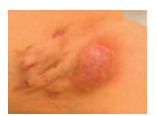

\section{ABSCESS}

Palpable lesion, with liquid content (pus), fluctuant, soft on palpation, diameter $>10 \mathrm{~mm}$, usually deep seated; acute, very painful phenomenon

FISTULA

Tract connecting deep suppurative cavities to each other or to the surface of the skin, sometimes oozing

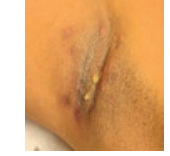

FISTULA

One or several long, mainly horizontal, permeable channels connecting 2 (or more) suppurative cavities and/or skin openings, draining or not

HYPERTROPHIC SCAR
Excessive growth of dense
collagen tissue, often red, pink,
or purple in appearance

\section{CORD}

Linear raised palpable lesion, unique or multiple; painful (spontaneously or on palpation) or not; inflammatory or not

FOLLICULAR PUSTULE

Raised lesion occurring at the hair follicle, with a liquid content - pus - and diameter $<10 \mathrm{~mm}$

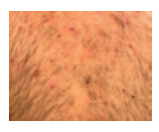

\section{FOLLICULAR PAPULE OR} PUSTULE

Raised inflammatory lesion, pointed and centred on the hair, with (pustule) or without (papule) a liquid content (pus), diameter $<10 \mathrm{~mm}$

SIMPLE OR DOUBLE COMEDOS

Break in the skin surface in the form of a simple or double orifice of a few millimetres filled with keratin

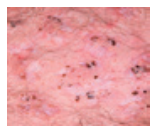
SIMPLE OR DOUBLE OPEN COMEDOS

Simple or double (interconnected) openings of the skin surface, $1-3 \mathrm{~mm}$ in diameter, filled with white substance, black on the top; non-inflammatory

EPIDERMOID CYST

Closed sac under the skin containing keratin and its breakdown products (suppressed)

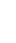

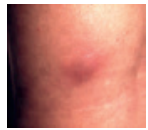 \\ E}




\begin{tabular}{|c|c|c|c|}
\hline \multicolumn{2}{|l|}{ a Preliminary set of definitions } & \multicolumn{2}{|l|}{ b Proposed set of definitions } \\
\hline Definition & Image & Definition & Image \\
\hline $\begin{array}{l}\text { HURLEY III } \\
\text { Diffuse or near-diffuse } \\
\text { involvement of } \geq 1 \% \text { body } \\
\text { surface area, with multiple } \\
\text { interconnected tracts, cords, } \\
\text { nodules, and abscesses across } \\
\text { an entire area with no normal } \\
\text { skin in between }\end{array}$ & & $\begin{array}{l}\text { HURLEY III } \\
\text { Diffuse or near-diffuse } \\
\text { involvement of } \geq 1 \% \text { body } \\
\text { surface area, with multiple } \\
\text { interconnected tracts, cords, } \\
\text { nodules and abscesses across an } \\
\text { entire area with no normal skin } \\
\text { in between }\end{array}$ & \\
\hline
\end{tabular}

Since the survey included 27 questions (8 definitions, 9 pathophysiological classifications, and 10 pictures) and the number of respondents was 81 , the maximum overall agreement rate was set to $2187 / 2187$ ( 81 participants $\times 27$ questions). We detected an overall agreement rate of $86.3 \%(1887 / 2187)$. Details on the agreement rate for each term's definition, pathophysiological classification, and picture are provided in Table 2.

As for the proposed definitions, disagreement rates $>10 \%$ were detected for all terms except Hurley III. The definitions of nodule, abscess, fistula, hypertrophic scar, follicular pustule, and simple or double comedos were therefore changed, taking into account the suggestions given by the respondents with their comments. Similarly, the term epidermoid cyst was removed from the list of HS typical lesions and the term pyogenic granuloma added, based on participants' comments (Table 1b).

Regarding the proposed pathophysiological classifications, the highest disagreement rates were found for face and scalp as special locations of HS (Table 2). These items were therefore excluded from the final set of HS typical lesions. Additionally, we decided to remove altogether the concept of pathophysiological classifications from the final set of HS typical lesions, based on numerous comments stating that this was beyond the scope of a clear and simple description of HS typical lesions (Table 1b).

As for the proposed pictures, the highest disagreement rates were found for nodule, abscess, fistula, hypertrophic scar, follicular pustule, and face and scalp as special locations of HS (Table 1). More illustrative pictures for these entities were therefore selected for the final set of HS typical lesions, apart from face and scalp as special locations of HS, which were excluded as already mentioned. The new pictures were chosen from the photographic databases of our departments by an expert panel selected among the authors (G.B.E.J., V.M. and J.R.; Table 1b).
Numerous comments were made by participants and were taken into account in order to elaborate the final version of the proposed set of HS typical lesions (Table 1b).

\section{Discussion}

Clinical observation often forms the basis of disease diagnosis and severity assessment in dermatology. Precise definitions of typical HS lesions are not fully provided by the current scientific literature, and confusion regarding HS terminology may possibly contribute to the great observer variation seen in clinical scores [9]. In order to reduce this, an unambiguous terminology to describe HS lesions is critical. Therefore, we carried out a survey of physicians dealing with the disease and attending the most important European congress about HS. The aim of the study was to create a list of lesions typically found in HS, and to provide a definition and an explanatory clinical picture for each.

Recently, Freysz et al. [6] and Lipsker et al. [7] proposed a glossary of purely descriptive terms specific to HS, from which they excluded the terms scar, abscess, and, less strictly, fistula and comedo, because they relate to nosography (which includes semiology, aetiology, and pathophysiology) [18] rather than semiology/morphology alone. Although we agree with Lipsker et al. [7] that abscess, fistula, and comedo are more nosographic than semiologic terms, we decided to keep them in our final list of HS typical lesions because (i) they refer to clinical situations that well represent the disease, (ii) they are commonly used in daily practice, and (iii) they are included in the majority of scoring tools for HS.

Regarding the nodule, its size was extensively discussed by the participants. The threshold varies in dermatological textbooks: $5 \mathrm{~mm}$ in Fitzpatrick's book [12], $20 \mathrm{~mm}$ in the book by Bolognia et al. [13], and defined by some as 
Table 2. Agreement and disagreement rates for each lesion type's definition, pathophysiological classification, and image

\begin{tabular}{|c|c|c|c|c|}
\hline HS lesion type & Definition & $\begin{array}{l}\text { Pathophysiological } \\
\text { classification }\end{array}$ & Image & Total agreement \\
\hline \multicolumn{5}{|l|}{ Nodule } \\
\hline Agree & 64/81 (79.0) & $73 / 81(90.1)$ & $69 / 81(85.2)$ & \multirow[t]{2}{*}{$206 / 243(84.8)$} \\
\hline Disagree & $17 / 81(21.0)$ & $0 / 81(0.0)$ & $5 / 81(6.2)$ & \\
\hline \multicolumn{5}{|l|}{ Abscess } \\
\hline Agree & 64/81 (79.0) & $72 / 81(88.9)$ & $71 / 81(87.7)$ & \multirow[t]{2}{*}{$207 / 243(85.2)$} \\
\hline Disagree & $16 / 81(19.8)$ & $3 / 81(3.7)$ & $3 / 81(3.7)$ & \\
\hline \multicolumn{5}{|l|}{ Fistula } \\
\hline Agree & $69 / 81(85.2)$ & $75 / 81(92.6)$ & $74 / 81(91.4)$ & \multirow{2}{*}{$218 / 243$ (89.7) } \\
\hline Disagree & $10 / 81(12.4)$ & $1 / 81(1.2)$ & $3 / 81(3.7)$ & \\
\hline \multicolumn{5}{|c|}{ Hypertrophic scar } \\
\hline Agree & $67 / 81(82.7)$ & $70 / 81(86.4)$ & $71 / 81(87.7)$ & \multirow[t]{2}{*}{$208 / 243(85.6)$} \\
\hline Disagree & $13 / 81(16.1)$ & $1 / 81(1.2)$ & $3 / 81(3.7)$ & \\
\hline \multicolumn{5}{|c|}{ Follicular pustule } \\
\hline Agree & $71 / 81(87.7)$ & $73 / 81(90.1)$ & $74 / 81(91.4)$ & \multirow[t]{2}{*}{$218 / 243(89.7)$} \\
\hline Disagree & $9 / 81(11.1)$ & $2 / 81(2.5)$ & $3 / 81(3.7)$ & \\
\hline \multicolumn{5}{|c|}{ Simple or double comedos } \\
\hline Agree & 64/81 (79.0) & $67 / 81(82.7)$ & $68 / 81(84.0)$ & \multirow[t]{2}{*}{$199 / 243(81.9)$} \\
\hline Disagree & $14 / 81(17.3)$ & $2 / 81(2.5)$ & $1 / 81(1.2)$ & \\
\hline \multicolumn{5}{|l|}{ Epidermoid cyst } \\
\hline Agree & $69 / 81(85.2)$ & $72 / 81(88.9)$ & $73 / 81(90.1)$ & \multirow[t]{2}{*}{$214 / 243(88.1)$} \\
\hline Disagree & $11 / 81(13.6)$ & $1 / 81(1.2)$ & $1 / 81(1.2)$ & \\
\hline \multicolumn{5}{|c|}{ Special location: face } \\
\hline Agree & - & $66 / 81(81.5)$ & $68 / 81(84.0)$ & \multirow[t]{2}{*}{$134 / 162(82.7)$} \\
\hline Disagree & & $9 / 81(11.1)$ & $5 / 81(6.2)$ & \\
\hline \multicolumn{5}{|c|}{ Special location: scalp } \\
\hline Agree & - & $67 / 81(82.7)$ & $67 / 81(82.7)$ & \multirow[t]{2}{*}{$134 / 162(82.7)$} \\
\hline Disagree & & $7 / 81(8.6)$ & $5 / 81(6.2)$ & \\
\hline \multicolumn{5}{|l|}{ Hurley III } \\
\hline Agree & $74 / 81(91.4)$ & - & 75/81 (92.6) & \multirow[t]{2}{*}{$149 / 162(92.0)$} \\
\hline Disagree & $4 / 81(4.9)$ & & $0 / 81(0.0)$ & \\
\hline \multicolumn{5}{|l|}{ Total agreement } \\
\hline Agree & $542 / 648(83.6)$ & $635 / 729(87.1)$ & $710 / 810(87.6)$ & $1,887 / 2187(86.3)$ \\
\hline
\end{tabular}

Data are presented as $n / N(\%)$. Numbers do not always add up to the total due to missing values (non-answers).

being $>10 \mathrm{~mm}$ [11]. The threshold of $10 \mathrm{~mm}$ seemed, then, a compromise between these different definitions. The nodules are usually deep-seated and barely visible. The only symptom is pain. They are, however, easily palpable [19]. The nodule can be also superficial. In this case, the other signs are usually present (erythema and heat).

The abscess could be considered as a particular kind of nodule, that is, a nodule filled with liquid. Obviously, not all nodules are abscesses: an abscess represents an acute, very painful phenomenon and needed, in our view, to be considered separately. The participants agreed that the hallmark of this lesion is the fluctuation. It is difficult to make the difference, clinically, with a simple nodule in a deep location since the fluctuating sign is often not discernible in that situation.

The terms sinus tract and tunnel proposed in comments by participants should be considered as synonyms of fistula according to Lipsker [20] if we follow a less exclusive semiology. They can be multiple and associated to a cord $[7,21]$. When applying pressure to one area, one may find oozing in another area. A single skin opening can be observed and is usually the result of the natural evolution of an abscess or the surgical incision of an abscess. The latter has better prognostic and less resis- 
tance to treatment than a real fistula, and hence it should be considered as a part of the abscess and not as a fistula [19].

On the other hand, the proposed term cord is to be preferred to the term hypertrophic scar, which is usually secondary to trauma (e.g., surgery or burn) and, contrary to the HS cord, tends to regress spontaneously over time $[6,22]$. We therefore decided to change the initially proposed term hypertrophic scar into cord, as was also suggested by comments provided by participants.

Concerning the follicular pustule, we added the papule, as suggested by comments, because liquid content (pus) is not always present. Inflammation is always encountered in such cases, so this was added to the final definition.

Simple or double open comedos are observed in the disease. There are no closed comedos in HS, which is why this was clarified in the final set [23]. They could also be named pseudo-comedos, as Boer and Jemec [14] suggested.

As for epidermoid cysts, some comments underlined that although they may represent the most common lesions in a small subset of patients, they are generally rare among HS patients [4]. Hence, we removed them from the final set of definitions. In addition, the definition provided in the preliminary set was more histopathological than clinical.

Based on comments, we decided to add multiple pyogenic granulomas that are more often found in the disease according to the expert opinion of the survey participants. They are the consequence of a chronic inflammation and suppuration, usually associated with Hurley III lesions [4].

We proposed in this survey that in cases of HS where lesions occur on the face and the scalp, this could represent the same disease, rather than an associated acne conglobata or dissecting cellulitis of the scalp. In the case of facial lesions (associated or not with back lesions), the poor clinical outcome with retinoids reinforces the suspicion of HS secondary lesions [23-25], but in both cases (facial and scalp lesions) the difference is difficult to define clinically and this distinction was controversial in the collected comments. Hence, it was eliminated from the final version for the sake of clarity.

HS is a complex disease and the recognition of the elementary lesions is very difficult when in more severe cases the lesions become confluent. The term Hurley III is used when it is impossible to describe and individualize lesions. Hurley III is indeed defined as the diffuse or neardiffuse involvement of an entire body area in which all lesions can be encountered together, forming a thick magma. For the buttock area, at least $1 \%$ of the body surface area (equivalent to the palm of one hand) should be diffusely involved in order to classify the disease as Hurley III. This has not yet been formalized by a published consensus, but it is commonly accepted by the vast majority of experts [17].

The aim of this study was to develop a clear and simple description of the lesions typically found in HS. Therefore, classification of lesions in primary, secondary, and associated - which refers to the pathophysiological process, as recently suggested by Micali [26] - was removed from the set.

The study had several limitations. Participants were invited to agree/disagree on definitions of HS typical lesions based on only one example picture of each lesion type: this may have produced higher agreement rates than those hypothetically obtainable using multiple example pictures for each lesion type, some of which may not be classic. Our investigation should then be regarded as an agreement study on lesion definitions, rather than an agreement on lesion recognition. Future studies in this field should focus on enhancing the skills of physicians in recognizing HS typical lesions using the definitions provided herein, and ultimately their ability to grade disease severity, activity, and response to treatments. Moreover, agreement rates were not reassessed after lesion definitions and images were changed and pathophysiological classification was removed. However, we would like to point out that these changes were made taking into account the respondents' comments. The proposed set of definitions and pictures produced in this study should be tested in a future study similarly including expert HS physicians. HS lesions cannot only be described correctly by sight. Therefore, association of definitions and images are helpful benchmarks. Our work set out to describe the external aspect of the lesions. The use of ultrasound could provide additional information regarding the internal aspect of the lesions [27, 28].

The main advantage of this study is to provide a benchmark to describe morphology in this complex disease. The set of definitions and images tested obtained a good general agreement rate among the participants of the 5 th Conference of the EHSF, which represents the most important European medical conference on this disease. Taking into consideration their numerous, useful comments, the definitions and pictures were refined to better describe the disease.

This project may help to support the development of the European Registry for HS in which the count of the 
lesions and several scores are required [29]. In the future, it could be also interesting to test this set on patients and to progress towards self-assessment by patients themselves. Furthermore, the project fits independently with the HISTORIC-defined core outcome set of physical signs and, thus, represents the synergy in current HS research $[30,31]$.

In conclusion, we proposed a user-friendly set of definitions and images of HS typical lesions, which, after further validation, could potentially serve as a tool to recognize the disease, score its severity, better assess the treatment efficacy, and standardize communication among physicians.

\section{Key Message}

We propose a set of lesion definitions/images for a better semiologic description of hidradenitis suppurativa.

\section{Statement of Ethics}

This study complies with the guidelines for human studies and includes evidence that the research was conducted ethically in accordance with the World Medical Association Declaration of Helsinki. The study was approved by the local ethics committee and informed consent was obtained for the publication of the images.

\section{Disclosure Statement}

The authors have no conflicts of interest to declare.

\section{Funding Sources}

There are no funding sources to declare.

\section{Author Contributions}

M.D., M.S., V.M., and J.R.: conception or design of the work. M.D., M.S., F.B., L.R.T., V.M., and J.R.: acquisition, analysis, or interpretation of data. M.D., M.S., J.W., G.B.E.J., V.M., and J.R.: drafting the work or revising it critically for important intellectual content. M.D., M.S., J.W., F.B., L.R.T., G.B.E.J., V.M., and J.R.: final approval of the version to be published.

\section{References}

1 Revuz JE, Canoui-Poitrine F, Wolkenstein P, Viallette C, Gabison G, Pouget F, et al. Prevalence and factors associated with hidradenitis suppurativa: results from two case-control studies. J Am Acad Dermatol. 2008 Oct;59(4): 596-601.

2 Jemec GB. Clinical practice. Hidradenitis suppurativa. N Engl J Med. 2012 Jan;366(2): $158-64$.

3 Revuz J. Hidradenitis suppurativa. J Eur Acad Dermatol Venereol. 2009 Sep;23(9): 985-98.

4 Jemec G, et al. Clinical aspects. Associated diseases: causality or complications? Nosology and classifications. In: Jemec G, Revuz J, Leyden J. Hidradenitis suppurativa. Berlin: Springer; 2006. chap 3, 6, 9.

5 Scheinfeld N. An atlas of the morphological manifestations of hidradenitis suppurativa. Dermatol Online J. 2014 Apr;20(4):22373.

6 Freysz M, Jemec GB, Lipsker D. A systematic review of terms used to describe hidradenitis suppurativa. Br J Dermatol. 2015 Nov; 173(5): 1298-300.

7 Lipsker D, Severac F, Freysz M, Sauleau E, Boer J, Emtestam L, et al. The ABC of hidradenitis suppurativa: a validated glossary on how to name lesions. Dermatology. 2016; 232(2):137-42.

Typical Lesion Definition in HS
8 van der Zee HH, Jemec GB. New insights into the diagnosis of hidradenitis suppurativa: clinical presentations and phenotypes. J Am Acad Dermatol. 2015 Nov;73(5 Suppl 1):S236.

9 Thorlacius L, Garg A, Riis PT, Bettoli V, Ingram J, Marmol V, et al. Reproducibility of outcome measure instruments used in $\mathrm{Hi}$ dradenitis suppurativa : an agreement and reliability study. Poster 25th EADV Congress; Vienna; 2016.

10 Daxhelet M, Suppa M, Benhadou F, Djamei V, Marmol V, Revuz J. Describe the HS lesions? More complex than it looks! Lecture 25th EADV Congress; Vienna; 2016.

11 Coulson IH, Benton EC, Stephanie Ogden S. Diagnosis of skin disease. In: Rook's textbook of dermatology. 9th ed. vol 1. Philadelphia (PA): Wiley Blackwell; 2016.

12 Garg A, Levin NA, Bernhard JD. Structure of skin lesions and fundamentals of clinical diagnosis. In: Fitzpatrick's dermatology in general medicine. 7th ed. vol 1. New York (NY): Mc Graw Hill Medical; 2008.

13 Bolognia JL, Jorizzo JL, Schaffer JV. Basic principles of dermatology and bacterial diseases. In: Bolognia JL, Jorizzo JL, Schaffer JV. Dermatology. 3rd ed. vol 1. London: Elsevier; 2012.
14 Boer J, Jemec GB. Mechanical stress and the development of pseudo-comedones and tunnels in hidradenitis suppurativa/acne inversa. Exp Dermatol. 2016 May;25(5):396-7.

15 Patterson JW. Cysts, sinuses, and pits. In: Patterson JW, editor. Weedon's skin pathology. 4th ed. Philadelphia (PA): Elsevier; 2015.

16 Hurley HJ. Axillary hyperhidrosis, apocrine bromhidrosis, hidradenitis suppurativa, and familial benign pemphigus: surgical approach. In: Roenigk RK, Roenigk HH, editors. Dermatologic surgery. New York (NY): Marcel Dekker; 1989. p. 729-39.

17 Revuz J. [Clinical evaluation of the severity of hidradenitis suppurativa]. Ann Dermatol Venereol. 2015 Dec; 142(12): 729-35. French.

18 Pinel P. Nosographie philosophique, ou la méthode de l'analyse appliquée à la médecine. Paris: Richard, Caille and Ravier; 1798.

19 Revuz J. Hidradenitis suppurativa: terminology. Dermatology. 2016;232(3):381.

20 Lipsker D. Reply to Revuz' letter entitled "Hidradenitis suppurativa: terminology". Dermatology. 2016;232(3):382.

21 Wortsman X. Reply to Lipsker et al. and Revuz on hidradenitis suppurativa terminology: the imaging point of view. Dermatology. 2016;232(4):520. 
22 Rabello FB, Souza CD, Farina Júnior JA. Update on hypertrophic scar treatment. Clinics (São Paulo). 2014 Aug;69(8):565-73.

23 Poli F, Wolkenstein P, Revuz J. Back and face involvement in hidradenitis suppurativa. Dermatology. 2010;221(2):137-41.

24 Revuz J, Poli F. [Acne conglobata: fact or fiction?]. Ann Dermatol Venereol. 2019 Jan; 146(1):1-3. French.

25 Poli F, Revuz J. [Acne flare on isotretinoin: A pointer to diagnosis of hidradenitis suppurativa]. Ann Dermatol Venereol. 2019 Jan; 146(1):4-8. French.

26 Micali G, editor. Hidradenitis suppurativa a diagnostic atlas. Hoboken (NJ): Wiley Blackwell; 2017.
27 Martorell A, Segura Palacios JM. [Ultrasound examination of hidradenitis suppurativa]. Actas Dermosifiliogr. 2015 Nov; 106 Suppl 1: 49-59. Spanish.

28 Wortsman X. Imaging of hidradenitis suppurativa. Dermatol Clin. 2016 Jan;34(1):59-68.

29 Daxhelet M, Suppa M, Benhadou F, Djamei V, Tzellos T, Ingvarsson G, et al. Establishment of a European Registry for hidradenitis suppurativa/acne inversa by using an open source software. J Eur Acad Dermatol Venereol. 2016 Aug;30(8):1424-6.
30 Thorlacius L, Ingram JR, Villumsen B, Esmann S, Kirby JS, Gottlieb AB, et al.; Hidradenitis Suppurativa Core Outcomes Set International Collaboration (HISTORIC). A core domain set for hidradenitis suppurativa trial outcomes: an international Delphi process. $\mathrm{Br}$ J Dermatol. 2018 Sep;179(3):642-50.

31 Thorlacius L, Garg A, Ingram JR, Villumsen B, Theut Riis P, Gottlieb AB, et al. Towards global consensus on core outcomes for hidradenitis suppurativa research: an update from the HISTORIC consensus meetings I and II. Br J Dermatol. 2018 Mar;178(3):71521. 